\title{
Passive damping of cables with MR dampers
}

\author{
F. Weber, G. Feltrin and M. Motavalli \\ Empa, Swiss Federal Laboratories for Materials Testing and Research, Structural Engineering Research Laboratory, \\ Überlandstrasse 129, CH-8600 Dübendorf, Switzerland
}

\begin{abstract}
This paper describes the measured damping characteristics of a cable with perpendicularly attached magnetorheological fluid damper. First, the damping of the free cable is measured for reference. Then, the magnetorheological fluid damper is connected to the cable in order to measure the resulting damping at different constant damper current levels. The experimental data shows clearly that the optimal current level providing maximum additional damping to one targeted mode is in inverse ratio to the mode number. Since the force trajectory at constant current of the MR damper under consideration describes nearly a Coulomb friction, the viscosity of an ideal viscous damper dissipating the same amount of energy is estimated. Also this equivalent viscosity depends in inverse ratio on the mode number. If the control target is maximum damping of several modes, the damper current hardly depends on the control target. Furthermore, the measurements demonstrate that external dampers lead to an increase of the structural resonance frequencies since MR dampers producing large forces at high current levels represent additional, fairly stiff supports. This is in contradiction to enhanced structural damping which evokes decreasing resonance frequencies.

1359-5997 @ 2005 RILEM. All rights reserved.

\section{RÉSUMÉ}

Cette publication décrit les caractéristiques d'amortissement mesurées sur un câble équipé d'un amortisseur à fluide magnétorhéologique (MR). L'amortissement du câble libre excité à l'aide d'un générateur de fonction est tout d'abord mesuré à titre de référence: Ensuite l'amortisseur MR est monté perpendiculairement sur le câble et l'amortissement du câble est mesuré pour différents niveanx de courant constant. Les résultats de mesure montrent clairement que le courant constant optimal pour obtenir un amortissement maximal d'un mode propre de vibration déterminé est inversement proportionnel au rang de ce mode. La trajectoire de la force de l'amortisseur MR utilisé décrivant pour un courant constant approximativement un frottement de Coulomb, il est possible d'estimer la viscosité équivalente d'un amortisseur visquetox dissipant la même quantité d'énergie. Cette viscosité équivalente est elle aussi inversement proportionnelle au rang du mode de vibration considéré. Si l'on désire obtenir un amortissement maximal de plusieurs modes de vibration propres, la valeur optimale du courant constant est alors quasiment indépendante de l'amortissement recherché. Les mesures réalisées montrent en outre que les amortisseurs externes conduisent à une élévation des fréquences de résonance de la structure sur laquelle ils sont appliqués; ceci s'explique par le fait que, avec les courants élevés ufilisés, les amortisseurs MR produisent des forces puissantes et constiment ainsi des appuis supplémentaires assez rigides. Ceci à l' inverse de l'amortissement structural qui conduit lui à des fréquences de résonance un peu plus basses.
\end{abstract}

\section{INTRODUCTION}

Magnetorheological (MR) fluid dampers combine some features which seem to be promising for vibration attenuation of stay cables and other civil structures:

- The damping force of MR dampers may be tuned to the actual vibration state [1]. Thus, MR dampers may be seen as a damping tool for engineers that allows for adjusting the damping force for maximum vibration suppression after their installation. Basically, any desired damper characteristic may be emulated using MR dampers provided that the damper force tracking task is solved with satisfactory accuracy. In contrast, passive dampers such as Elastomer dampers are first designed and then installed. Due to slightly wrong assumptions within the design process, Elastomer dampers may provide suboptimal damping.

- MR dampers connected to stay cables represent failsafe systems due to the residual friction and dissipative nature of MR dampers [2]. 
- MR dampers provide higher friction forces than electrorheological fluid dampers for the same damper housing dimensions [3].

- Since they are connected perpendicularly, these MR devices do not have to support the large static cable tension and therefore they can be attached to stay cables after their erection.

Summarizing, MR dampers are tuneable dampers that can be connected to civil structures after their erection if unexpected undesirable vibrations occur.

In order to keep effort and expense of control software and hardware as small as possible on cable-stayed bridges, MR dampers are usually operating at constant current level in the case of cable vibrations above a certain threshold [4], [5]. Otherwise, the current is zero. Despite this simplicity, the determination of the optimal constant current value for maximum vibration reduction is not trivial.

This paper describes the experimental work for measuring the damping of a free cable and of a cable with MR damper at constant current level. Then, the optimal constant current is determined for two control targets. Finally, the dependency of the constant current on the control target is discussed and compared to the theory of optimal viscous damping $[7,8]$.

\section{SYSTEM DESCRIPTION}

\subsection{Test set-up}

The system under consideration is a steel wire strand of $15.5 \mathrm{~m}$, see Figs. 1 and 2, [6]. The MR damper position is $0.775 \mathrm{~m}$, which corresponds to $5 \%$ of the cable length. The damper is located near the anchorage because of the following two reasons:

1. According to [7], maximum supplemental modal damping ratio for mode one using a linear viscous damper located at $2 \%$ becomes approximately $1 \%$ (Equation (1), the index $j$ denotes the mode number). As experimental tests demonstrate, this may be sufficient for suppressing the first mode [9].

2. A damper position within $2 \%$ to $5 \%$ results also from the practical point of view that cable length, cable inclination, and damper cylinder length do only allow for installing dampers within a certain range.

$\zeta_{j} \approx \frac{1}{2} \cdot j \cdot \frac{x_{d}}{L}=\frac{1}{2} \cdot 1 \cdot 2 \%=1 \%$

Thus, the chosen MR dainper position on the cable setup represents the real case. The wind and traffic loading exciting the stays are simulated by an electro dynamically driven shaker which is controlled by a signal generator. The shaking mass is rigidly connected to the cable at $14.34 \mathrm{~m}$. This position enables to excite the first ten cable modes.

\subsection{Measured cable properties}

Both the mass per unit length $(1.17 \mathrm{~kg} / \mathrm{m})$ and the cable tension $(33.4 \mathrm{kN})$ are known by static measurements. In contrast, the determination of the resonance frequencies and

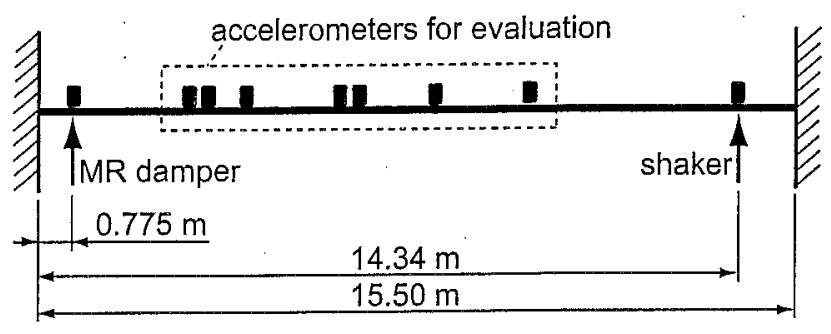

Fig. 1 - Scheme of test set-up.

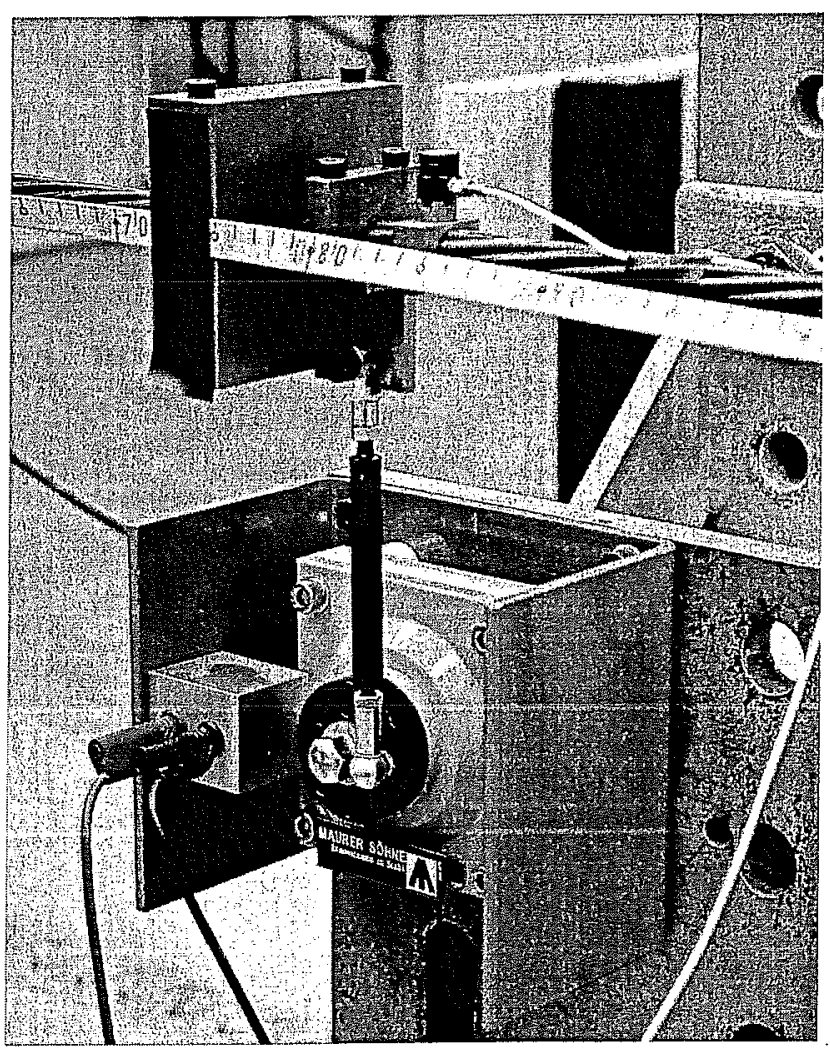

Fig. 2 - Test cable with accelerometer and rotational MR damper.

modal damping ratios require dynamic measurements that are described in the following.

Applying an impact hammer stroke to the cable, the resonance frequencies may be determined by Fourier analysis of the measured accelerations. The accelerometers are located on the cable such that the first twenty modes are detectable (Fig. 1).

When estimating the modal damping ratio from experimental data, the common way is to measure the natural decay of the excited structure and to determine the logarithmic decrement $[10,11]$. Therefore, the cable without MR damper is excited by the shaker exactly at the resonance frequencies of the first eight modes. After the time when the cable shaker system has reached steady-state conditions, the shaker control signal is turned off. The natural decay of the cable with rigidly connected shaking mass (Figs. 3 and 4) is measured by the seven accelerometers located between damper and shaker.

Exciting the cable with a white roise signal, then band pass filtering the signals in order to extract each mode and derive the modal damping ratios does hardly work. The reason is that 
the resonance frequencies are that near to each other that band pass filtering is not able to completely separate the modes. Not negligible modulation effects will result. Even when exciting the cable only at one single resonance frequency, some small modulation effects occur (Fig. 4 a).

The following post processing procedure is applied to every accelerometer signal in order to determine the damping ratio:

1. High pass filtering of accelerometer signal. This step is necessary if piezo-electric accelerometers are used due to their constant electrical charge.

2. Determination of the local maxima during the decay time (circles in Figs. 3 a and 4 a).

3. According to the formula for the logarithmic decrement for one cycle (Equation (2)), the natural logarithms of these local maxima describe theoretically a linear function. Thus, fitting these values by a linear function over $n$ cycles will produce the best estimate of the logarithmic decrement (Figs. 3 $b$ and $4 b$, Equation (3)).

4. Determination of damping ratio averaged over all $k$ accelerometers (Equation (4)). This step is necessary since the sensor position has strong influence on the accuracy of the signal reconstruction of the modes to be detected.

$$
\begin{aligned}
& \delta=\ln \left(\frac{\ddot{r}\left(t_{i}\right)}{\ddot{r}\left(t_{i}+T_{d}\right)}\right)=\ln \left(\ddot{r}\left(t_{i}\right)\right)-\ln \left(\ddot{r}\left(t_{i}+T_{d}\right)\right) \\
& \bar{\zeta}_{k}=\frac{\bar{\delta}_{k}(n \text { cycles })}{\sqrt{4 \pi^{2}+\bar{\delta}_{k}^{2}(n \text { cycles })}} \\
& \bar{\zeta}=\frac{1}{\text { num }_{s}} \sum_{k=1}^{n u m_{s}} \bar{\zeta}_{k}
\end{aligned}
$$

The resonance frequencies are not equally spaced in frequency due to the shaker on the cable (Table 1). According to [12], the material damping quantity of steel structures lies within the range of $0.1 \%$ to $0.2 \%$. Consequently, the measured values of the damping ratios of the lower modes (1-4) indicate that the relatively large displacements of these modes evoke energy dissipation within bearings and joints and, in this special case, between the steel wires of the steel wire strand. In contrast, the measured damping ratios of the higher modes (58) lie within the usual range and therefore show material damping. The reason for the rather large values for modes 2 and 3 may be the rigidly connected shaker mass, which is hold in its medium position by elastic rubber ribbons.

\subsection{MR damper}

The MR damper is a prototype rotational MR damper [13]. The maximum damper force needed to optimally damp the first cable mode according to [7] with the maximum achievable cable displacement of the test cable under consideration was estimated by simulation. According to this specification, the damper was manufactured by the industrial partner of the current research project. The measured steady-state behaviour of the MR damper shows the following main properties:

1. In the preyield region (Fig. 5), where the fluid does almost not flow, the fluid behaves more as a rigid body with very small elastic deformation [4], [14-16]. This explains the negative stifiness term indicated by the non-dissipative force values. Hence, when the
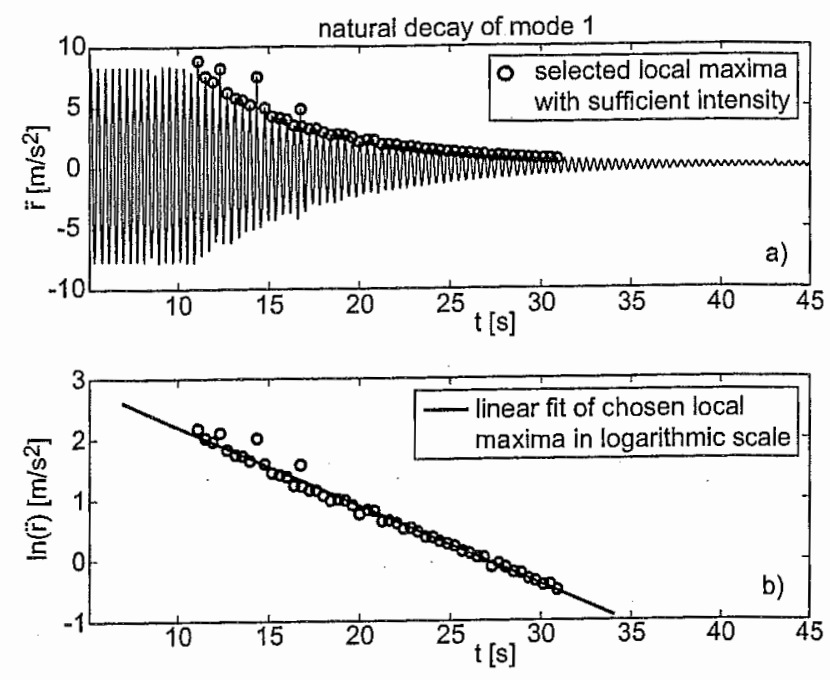

Fig. 3 - Measured natural decay of mode 1 (a) and corresponding linear fit of local maxima in logarithmic scale (b).
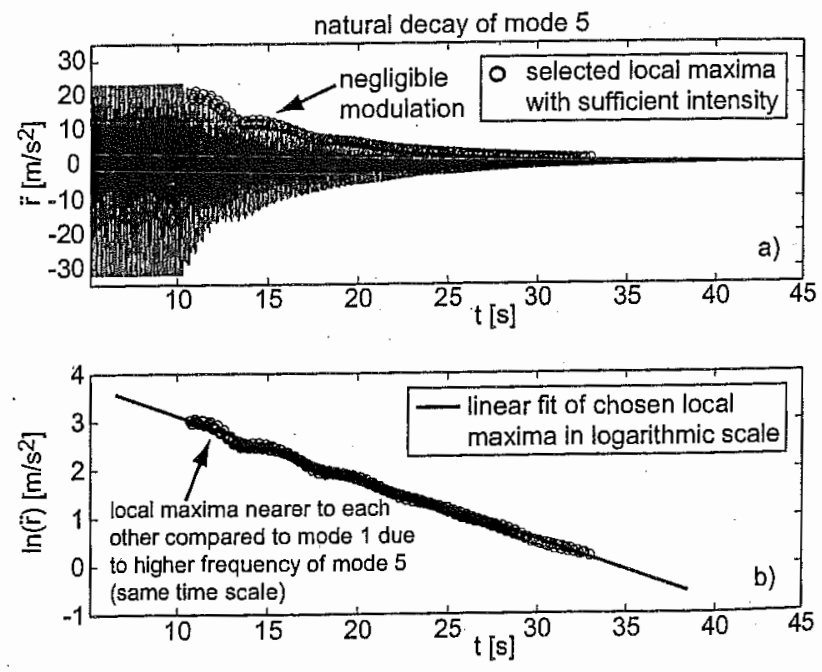

Fig. 4 - Measured natural decay of mode 5 (a) and corresponding linear fit of local maxima in logarithmic scale (b).

\begin{tabular}{|c|c|c|}
\hline \multicolumn{3}{|c|}{$\begin{array}{c}\text { Table 1 - Measured eigenfrequencies and modal } \\
\text { damping ratios of the cable without damper }\end{array}$} \\
\hline mode & $f[\mathrm{~Hz}]$ & $\bar{\zeta}[\%]$ \\
\hline 1 & 2.48 & 0.836 \\
\hline 2 & 4.49 & 1.95 \\
\hline 3 & 6.02 & 1.36 \\
\hline 4 & 8.23 & 0.564 \\
\hline 5 & 10.75 & 0.194 \\
\hline 6 & 13.33 & 0.116 \\
\hline 7 & 15.93 & 0.139 \\
\hline 8 & 18.62 & 0.111 \\
\hline
\end{tabular}


velocity changes its sign, the MR damper accelerates for a very short moment the structure $[17,18]$.

2. The force overshoot, which results primarily from the stiction phenomenon of the MR fluid and secondarily from the fluid mass, is small compared to the force value $[19,20]$.

3. In the postyield region, where the fluid starts to flow, the velocity profile and the chains are built up. The dynamics, which produce the maximum friction force to occur in advance of the velocity maximum, are also observed in $[13,17]$ and are a topic of current research.

4. The minimum friction force of approximately $20 \mathrm{~N}$, mainly caused by the seal and the residual fluid friction at $0 \mathrm{~A}$ (Fig. 6), is fairly small. The maximum friction force at $4.0 \mathrm{~A}$ is approximately $300 \mathrm{~N}$. Even for the lowest cable mode and for maximum shaker force, $300 \mathrm{~N}$ are too large for maximum damping. Thus, the optimal damper forces for the cable under consideration will not be constrained by minimum and maximum damper forces.

\section{CABLE WITH PASSIVE MR DAMPER}

\subsection{Testing procedure}

The damping of the entire cable damper structure is measured at constant damper current levels of $0.00,0.20$, $0.40, \ldots, 3.60$ and $3.80 \mathrm{~A}$. For these experiments, the shaker excites the cable by a sweep function. The properties of the sweep function (Table 2) are chosen the way that:

- The excitation frequency increases slowly so that the measurements are taken under nearly steady-state conditions.

- At least the first eight modes are excited.

For reference, the same experiment is done for the cable without MR damper.

\subsection{Measured vibration attenuation}

During the time of one full sweep function, the cable vibrations are measured by the seven accelerometers for evaluation (Fig. 1). First, the accelerations are high pass filtered and integrated over the time, Equation (5). This yields the vibration velocities. Then, the power spectral density of the seven velocities is estimated via Welch's method (PSD). Finally, these seven velocity spectra are averaged in the frequency domain in order to get one spectrum representing the vibration state of the cable part between MR damper and shaker, Equation (6).

$$
\begin{aligned}
& \dot{r}_{i, k}=\dot{r}_{i-1, k}+\frac{\ddot{r}_{i, k}}{f_{\text {mea }}} \\
& \overline{P S D}(\dot{r})=\frac{1}{\text { num }_{s}} \sum_{k=1}^{\text {num }_{s}} P S D\left(\dot{r}_{k}\right)
\end{aligned}
$$

The influence of the damper current and damper force, respectively, on the magnitudes and frequencies of the

\begin{tabular}{|c|c|c|}
\hline \multicolumn{3}{|c|}{ Table 2 - Properties of sweep excitation } \\
\hline$f_{\text {start }}[\mathrm{Hz}]$ & $f_{\text {stop }}[\mathrm{Hz}]$ & sweep time [s] \\
\hline 0.5 & 24.5 & 300 \\
\hline
\end{tabular}

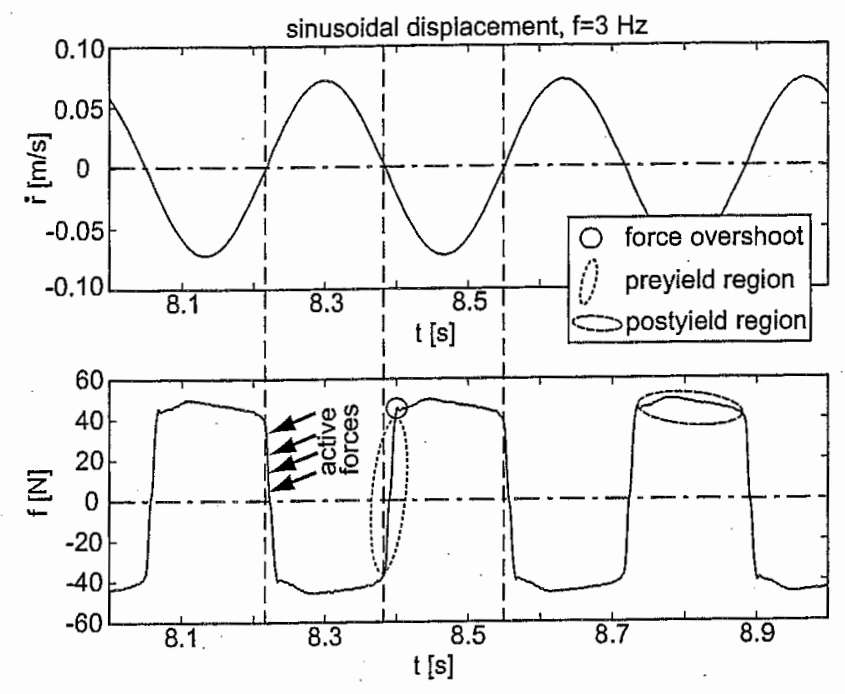

Fig. 5 - MR damper force response on sinusoidal rod displacement (here depicted the rod velocity) at $1.0 \mathrm{~A}$.

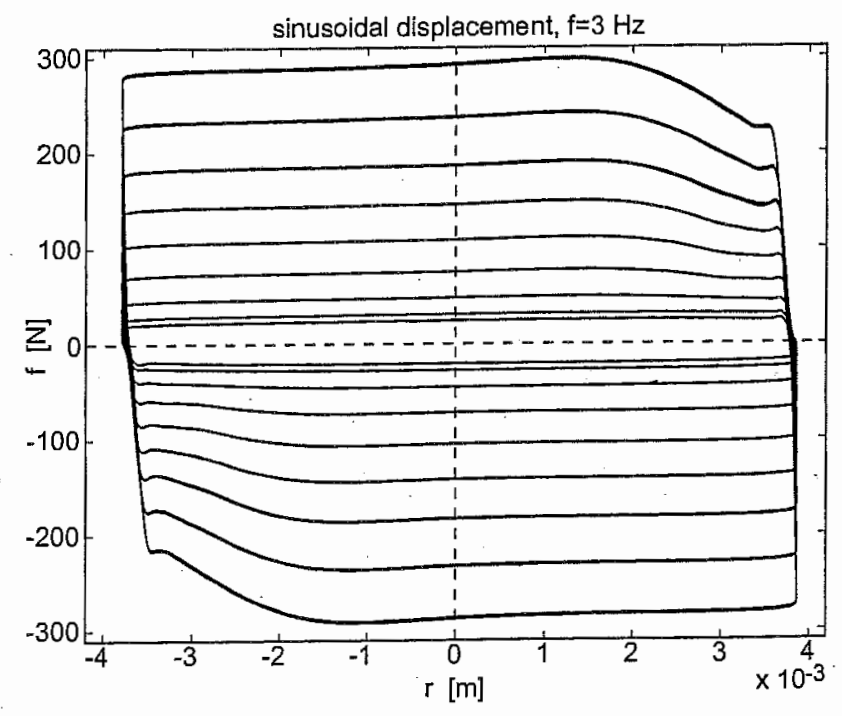

Fig. 6-MR damper force versus rod displacement at constant current levels.

excited modes is not visible if plotting the mean spectrum over the entire frequency range of the first eight modes. Therefore, the following eight figures (Figs. 7 to 14) depict the same mean spectrum but with different scaling on the $\mathrm{x}$ and $y$-axes, respectively. For better readability, only each second spectrum $(0.00,0.40, \ldots$ A) is depicted.

At small currents, the damper force is too small for large additional damping. For increasing currents, the resonance peaks decrease due to increasing damper forces. Above a certain current level, the magnitudes increase again because the MR damper clamps the cable, first, at small velocities, then, for further increasing currents, at larger velocities. Clamping means that the damper displacement vanishes 


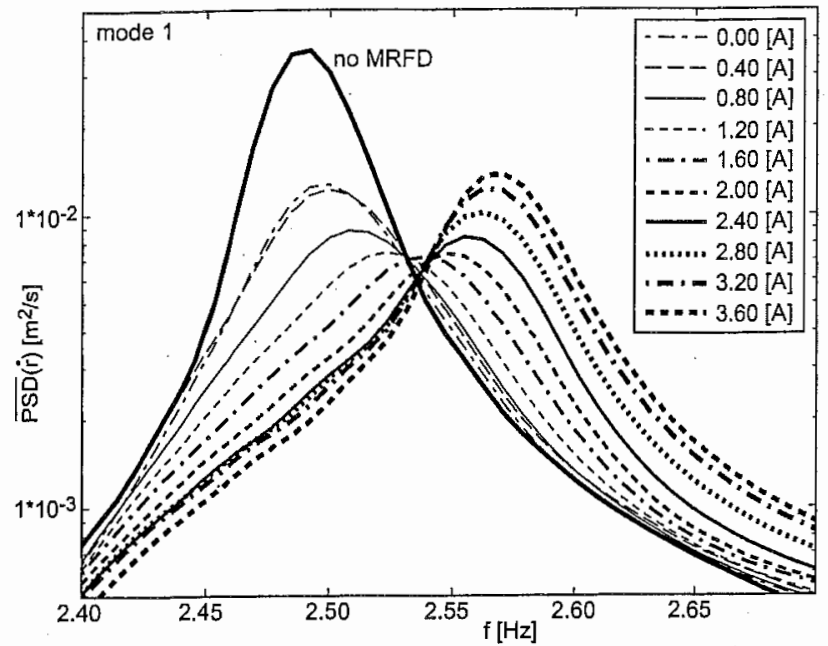

Fig. 7 - Measured resonance peak reduction of mode 1 comparing the free cable and the cable with MR damper.

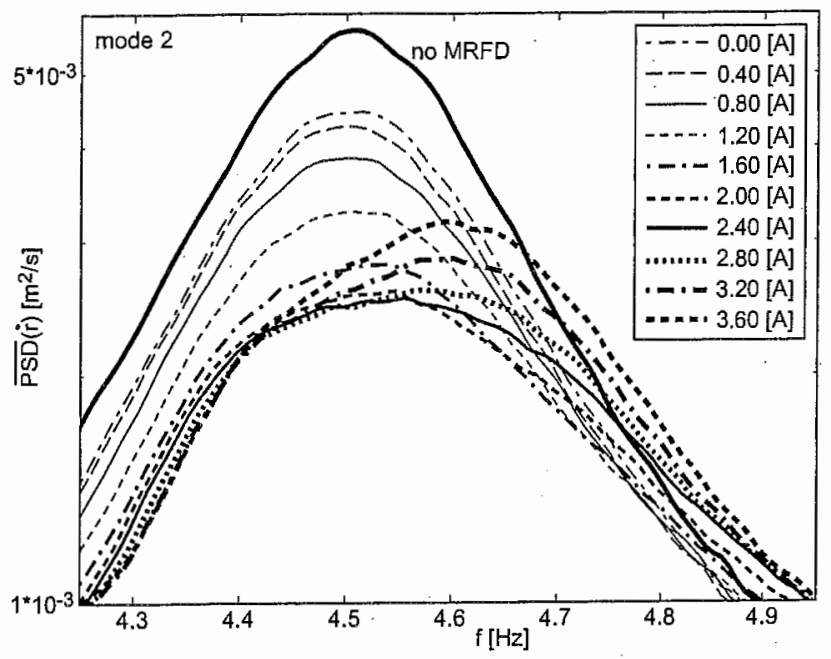

Fig. 8 - Measured resonance peak reduction of mode 2 comparing the free cable and the cable with MR damper.

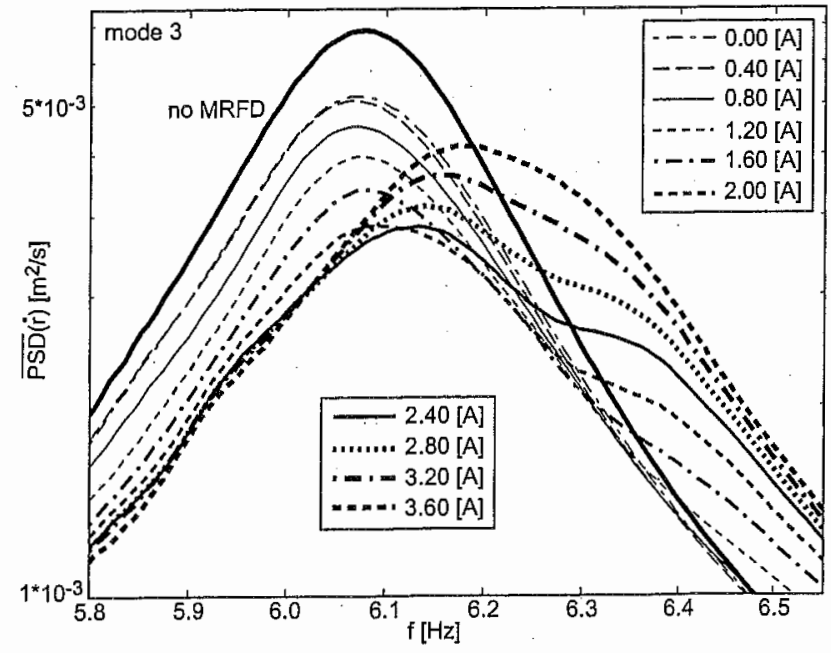

Fig. 9 - Measured resonance peak reduction of mode 3 comparing the free cable and the cable with MR damper.

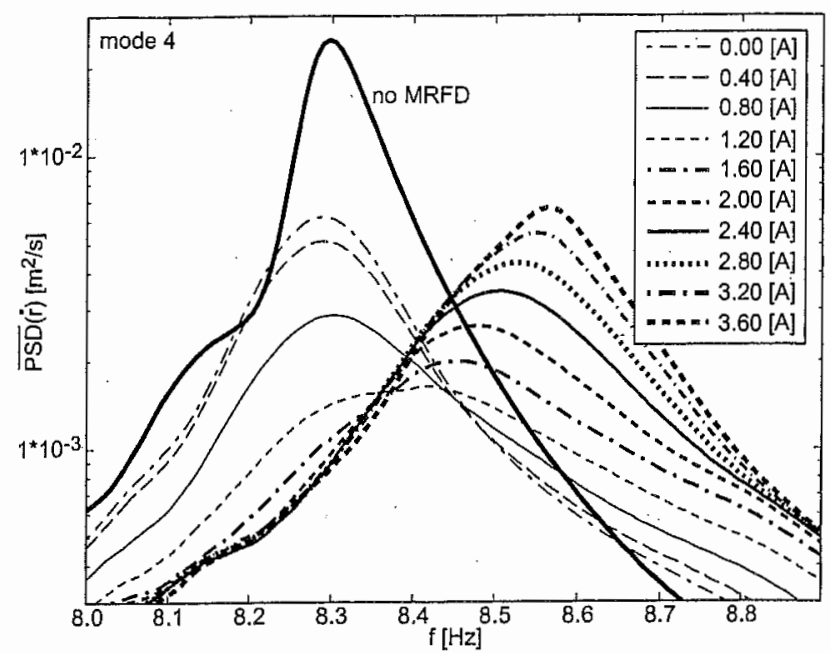

Fig. 10 - Measured resonance peak reduction of mode 4 comparing the free cable and the cable with MR damper.

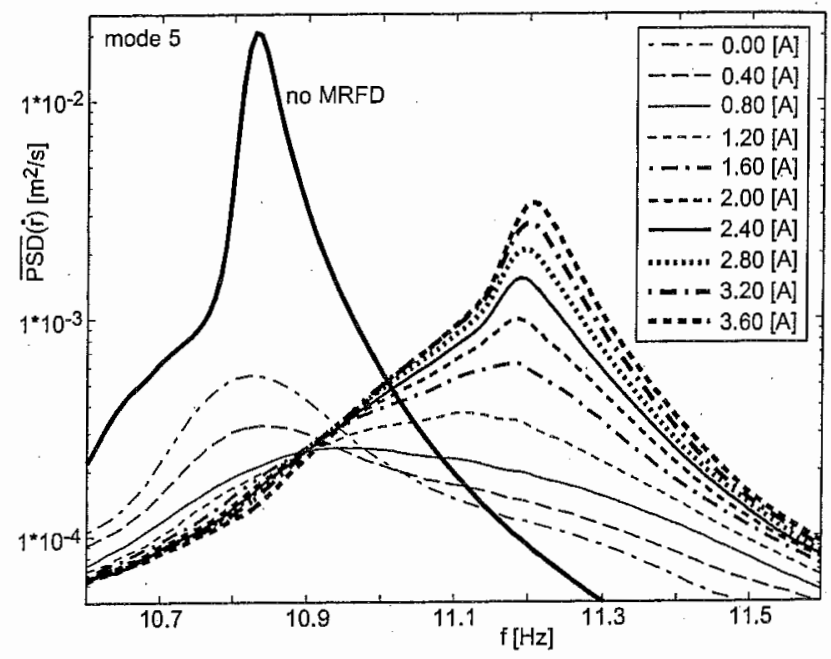

Fig. 11 - Measured resonance peak reduction of mode 5 comparing the free cable and the cable with MR damper.

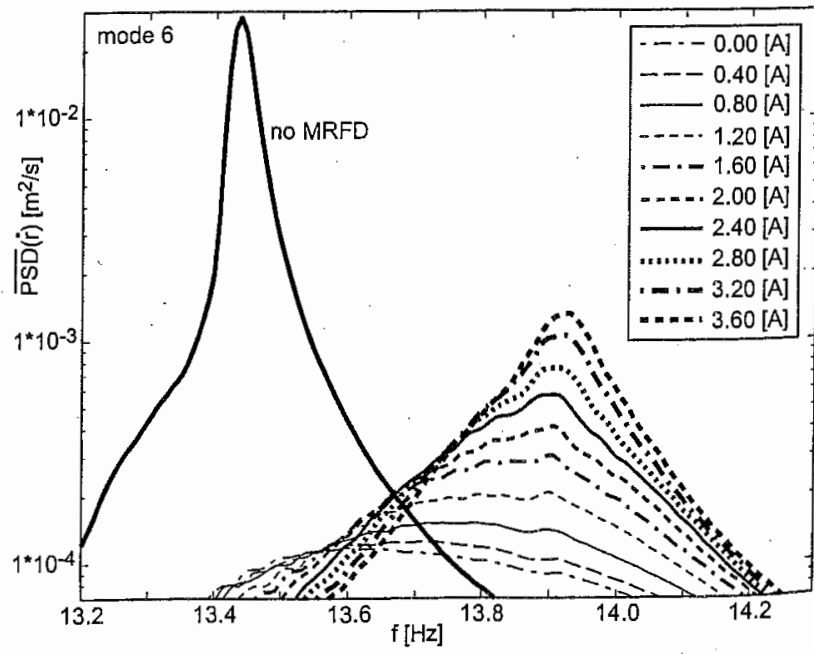

Fig. 12 - Measured resonance peak reduction of mode 6 comparing the free cable and the cable with MR damper. 


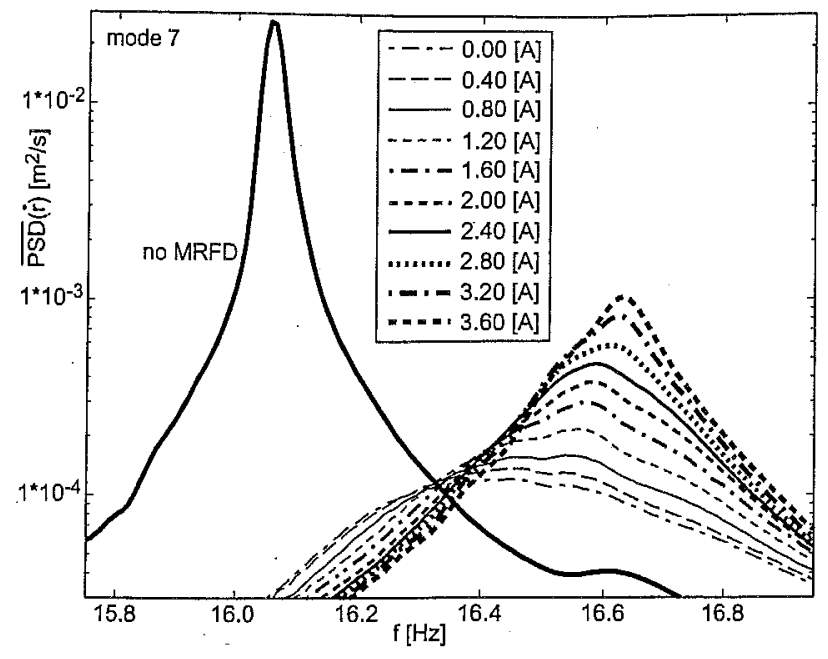

Fig. 13 - Measured resonance peak reduction of mode 7 comparing the free cable and the cable with MR damper.

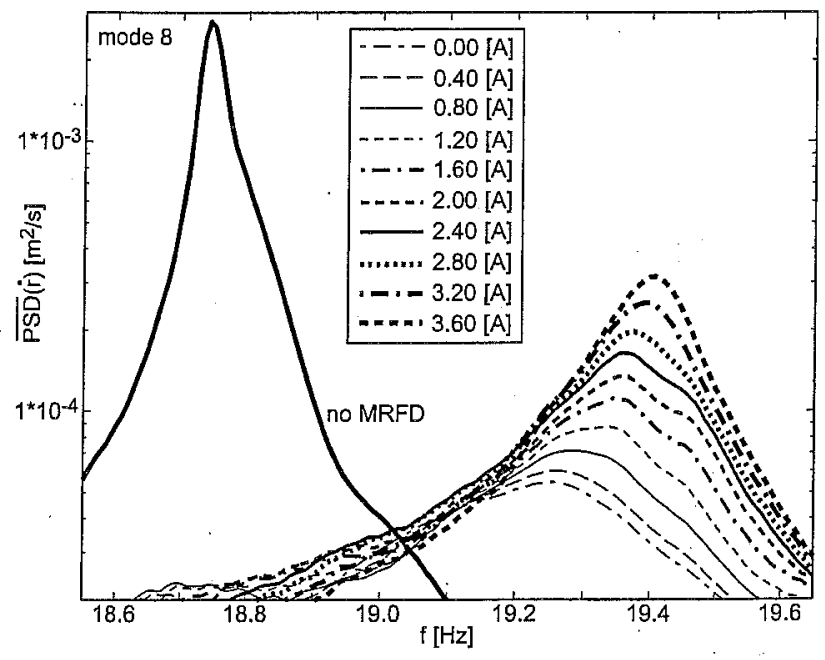

Fig. 14 - Measured resonance peak reduction of mode 8 comparing the free cable and the cable with MR damper.

due to too large damper forces and therefore energy may not be dissipated within the MR damper [21]. At maximum current of 3.80 A, the MR fluid becomes that stiff that the damper rod moves only during the first couple of cycles.

The frequency shift of the resonance frequencies is due to the MR damper connected perpendicularly to the cable [22]. Larger damper current is equivalent to an additional cable support with increased damping. At large current, this support is fairly stiff due to the clamping effect. Then, the vibrating cable seems to become shorter and the resonance peaks shift to higher frequencies.

As can be observed from Figs. 7 to 14, lower modes require larger damper forces for maximum additional damping and vice versa. This corresponds to the theory of optimal damping described in [7] and [8].

\section{OPTIMAL PASSIVE DAMPING}

As mentioned above, the constant current value producing maximum vibration suppression depends on the mode number. Therefore, the determination of the optimal constant current for maximum damping requires the definition of a damping or control target, respectively. In the following, the measurement data is evaluated for two different control targets.

\subsection{Maximum damping of one mode}

The first control target is maximum vibration mitigation of mode $j$. This criterion is reasonable in the case of one predominant mode. The peak reduction of the targeted mode is defined as follows

$\Delta(I)_{j}:=\frac{\overline{P S D}(n o M R)_{j}-\overline{P S D}(I)_{j}}{\overline{P S D}(n o M R)_{j}}$

Then, the optimal constant current yields

$\max \left(\Delta(I)_{j}\right) \rightarrow I=I_{o p t, j}$

From Figs. 15 and 16 can be observed that higher modes require smaller damper current levels and hence smaller damper forces (Fig. 17) for maximum damping.

According to [8], the optimal viscosity of an external linear viscous damper for maximum additional modal damping of a linear cable is given by

$c_{o p t, j}=\frac{\kappa_{\max }}{j} \cdot m L \omega_{1} \cdot \frac{1}{x_{d} / L}$

with the first circular frequency of the undamped cable

$\omega_{1}=\pi \sqrt{\frac{T}{m L^{2}}}$

and the non-dimensional damping parameter $\kappa$, which has to be chosen for maximum supplemental damping according to

$\max \left(\frac{\zeta_{j}}{x_{d} / L}\right)=\frac{\pi^{2} \kappa_{\max }}{\left(\pi^{2} \kappa_{\max }\right)^{2}+1}$

Thus, for a given damper position, the main influence on the optimal viscosity is the mode number $j$ (Equation (9)). In order to compare this relation with the measurement data, the constant damper force of the MR damper under consideration must be transformed to an equivalent viscosity of an ideal viscous damper. This is done by the idea that the equivalent viscous damper must dissipate the same amount of energy as the MR damper providing a Coulomb friction at constant current [10] (Fig. 18), thus

$4 \cdot f_{\max -c o u} \cdot r_{\max -\mathrm{cou}}=\pi \cdot f_{\max -v i s} \cdot r_{\max -v i s}$ 


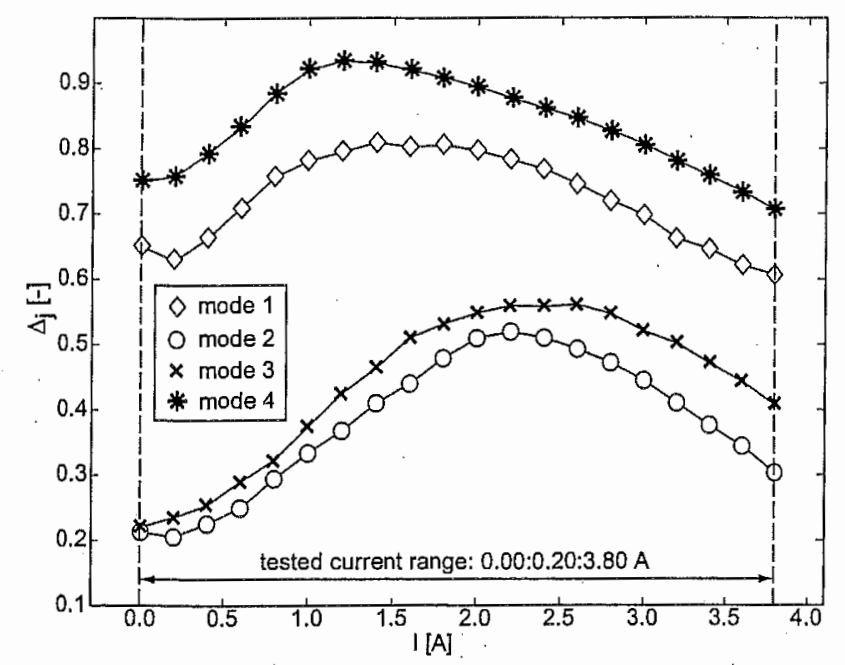

Fig. 15 a - Relative peak reduction of one targeted mode.

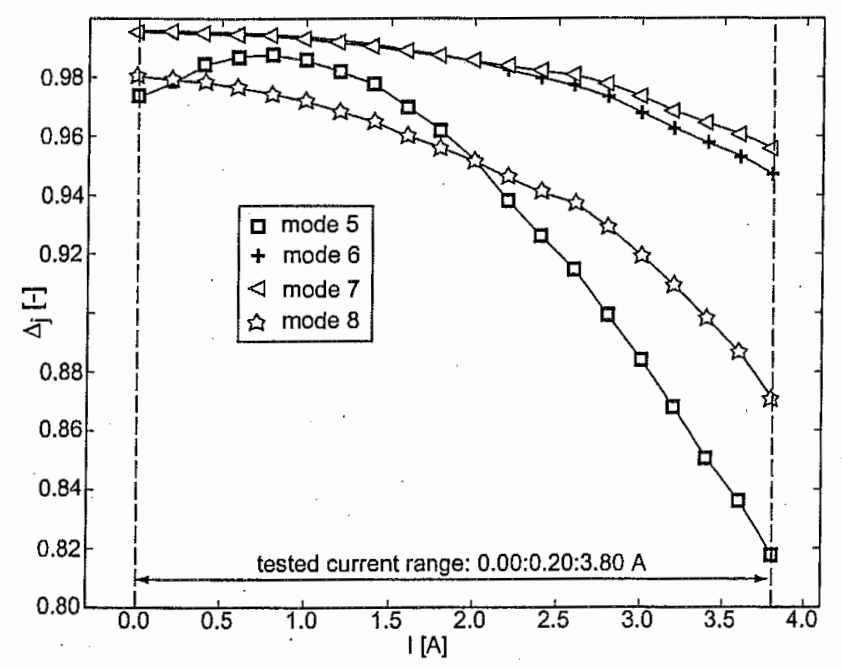

Fig. $15 \mathrm{~b}$ - Relative peak reduction of one targeted mode.

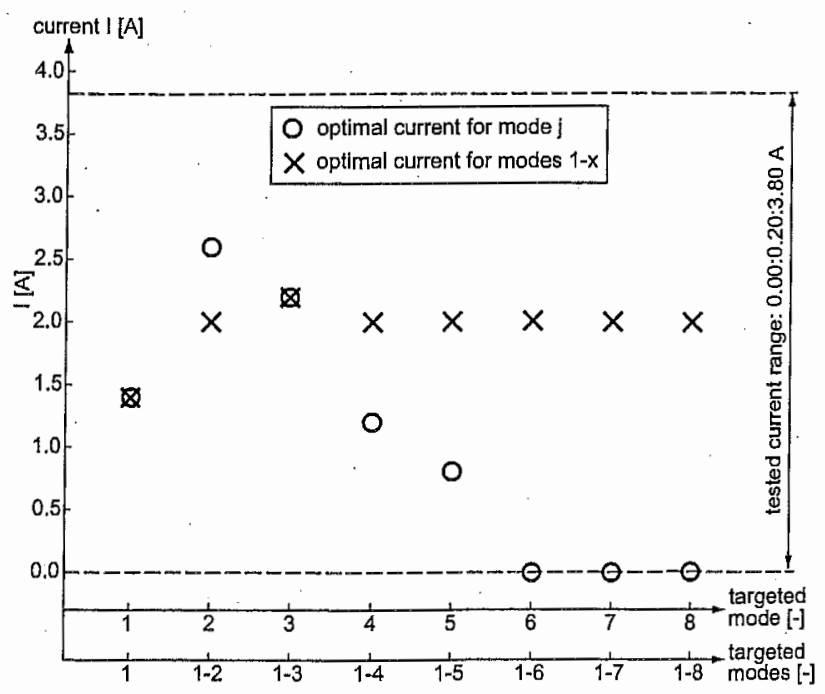

Fig. 16 - Optimal constant damper current for maximum damping depending on the control target.

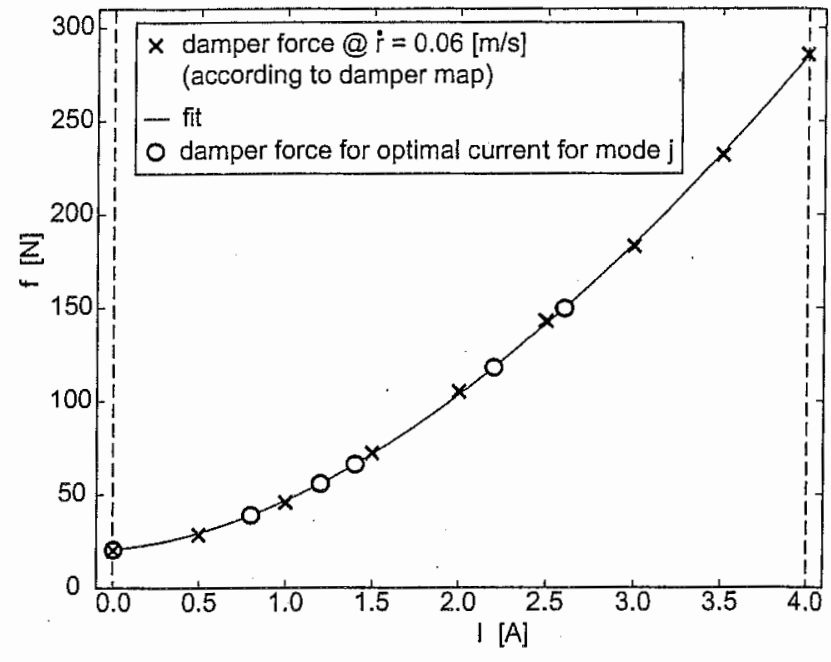

Fig. 17-Damper force corresponding to the optimal current for maximum damping of one targeted mode.

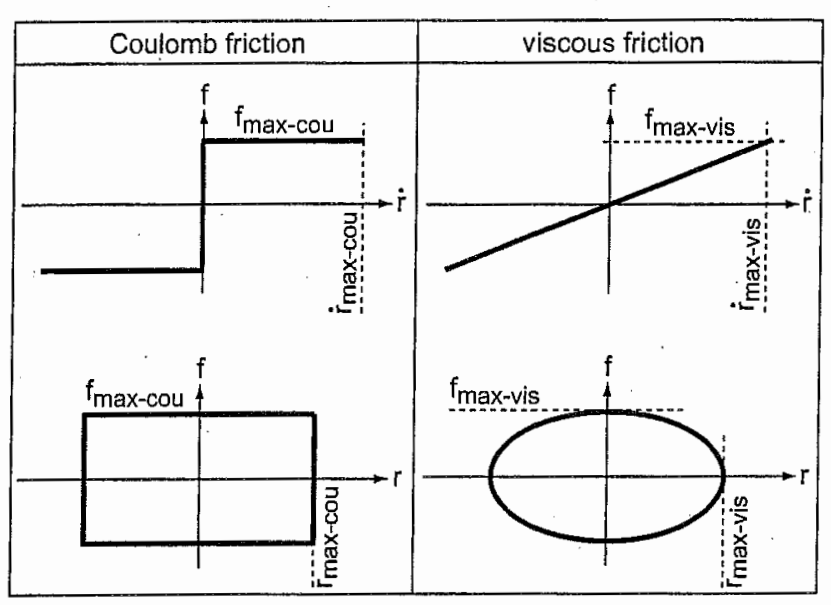

Fig. 18 - Force-velocity and force-displacement trajectories for Coulomb friction and viscous friction.

Then, the equivalent viscosity becomes

$c=\frac{f_{\max -v i s}}{\dot{r}_{\max -v i s}}=\frac{4 \cdot f_{\max }-c o u}{\pi \cdot \dot{r}_{\max -v i s}} \cdot \frac{r_{\max -c o u}}{r_{\max -v i s}}$

Assuming that both the displacements and velocities at damper position of both the Coulomb fiction damper and viscous damper are approximately equal, the equivalent viscosity may be estimated as follows

$c \approx \frac{4 \cdot f_{\max -c o u}}{\pi \cdot \dot{r}_{\max -c o u}}$

The values of the estimated viscosities are plotted versus the mode to be damped in Fig. 19. Similarly to the optimal damper force, the estimated equivalent viscosity depends on the mode number according to Equation (9) except for the first mode. This observation might be explained by:

- the bending stiffness of the steel wire strand, and

- the friction forces between the wires.

The cable displacement reducing effect of the bending stiffness is predominant in the case of the first mode due to the 
large displacements. Hence, the optimal viscosity for maximum damping of the first mode will be smaller than the optimal viscosity for a cable without bending stiffness. The friction forces between the steel wires dissipate vibration energy. This effect decreases the value of the optimal viscosity since some vibration energy is already dissipated. Again, the energy dissipation by friction between the steel wires may not be negligible for large displacements that occur during the first mode. Summarizing, both effects reduce the cable displacement and behave therefore like a damping element. Consequently, the additional MR damper does not have to add that much damping anymore, which leads to a smaller viscosity than expected by the theory.

The estimated equivalent viscosity is compared to the theoretically optimal viscosity (Fig. 20). Since the mass of the shaker is a "concentrated" mass at one cable position, the optimal viscosity is determined for the case, where the shaker mass is taken into account for the cable mass per unit length and for the case without shaker mass.

The comparison between the experimentally and
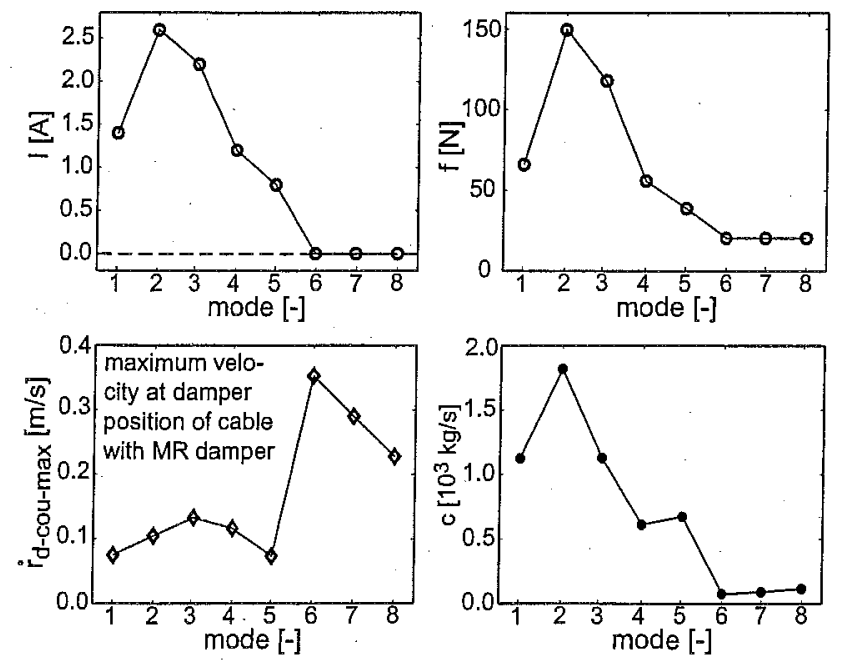

Fig. 19 - Estimated viscosity of an equivalent viscous damper for maximum damping of one targeted mode.

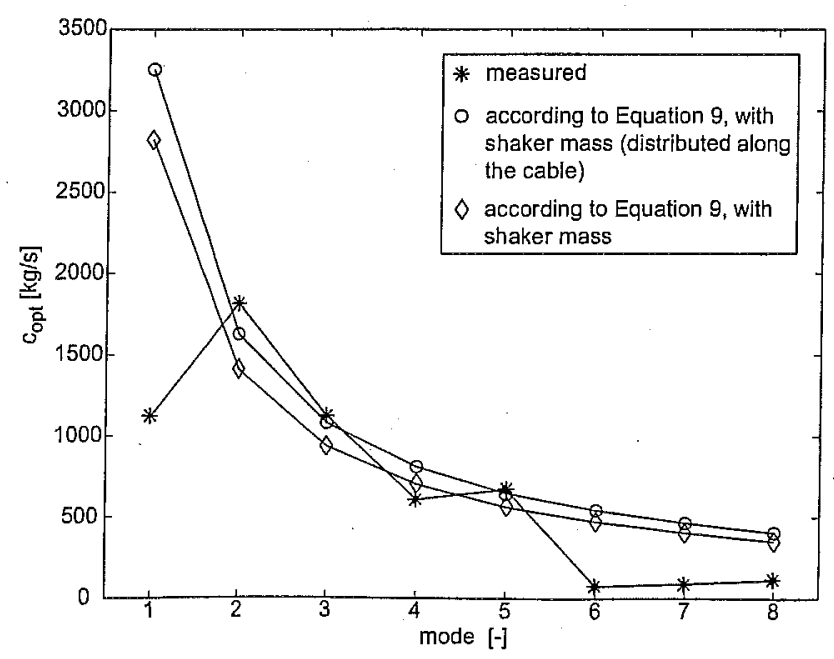

Fig. 20 - Comparison between measured and theoretically predicted optimal viscosity. theoretically determined optimal viscosities shows a good agreement for modes 2-5 (Fig. 20). The measured viscosity of the first mode is far smaller than the theoretical value for the reasons explained above. The reason for the large difference between measured and theoretical values for modes 6-8 may be out-of-plane vibrations that become more important for higher modes. Since the MR damper works only in one plane, the damper force may only be tuned to the vibration component in the damper axis, which ends up in a smaller equivalent viscosity than expected.

\subsection{Maximum damping of several modes}

The second control target is maximum suppression of vibrations due to the first $x$ modes. This control target may make sense when, e.g., the first three cable modes must be damped maximally because they cause the main visible undesirable cable displacement. The resonance peak reduction of several modes is defined as follows

$\Delta(I)_{(1-x)}:=\frac{1}{x} \sum_{j=1}^{x} \Delta(I)_{j}$

Accordingly, the optimal constant current becomes $\max (\Delta(1-x)) \rightarrow I=I_{\text {opt },(1-x)}$

As Figs. 21 and 16 depict, the dependency of the optimal constant current on the control target does not describe the relation of Equation (9) and is almost not dependent on the control target. The reason is that the optimal damping forces of higher modes are far smaller than for lower modes.

\section{CONCLUSIONS}

The optimal constant current value of an MR damper connected to a vibrating steel wire strand has been determined experimentally for the following two control targets:

1. maximum damping of one targeted mode, and

2. maximum damping of mode 1 to mode $x$.

Due to the Coulomb friction behaviour of the MR damper at constant current under consideration, the optimal constant current value has been converted to an estimated viscosity of an equivalent viscous damper, which dissipates the same amount of energy. The estimated equivalent viscosity turned out to be:

- in good agreement with the values of the theoretically optimal viscosity of modes $2-5$ for maximum damping of one targeted mode.

- far smaller than the theoretical value for mode 1 due to the cable displacement reducing effects such as friction between the steel wires of the steel wire strand and the bending rigidity of the cable. Both effects are not negligible for large displacements, thus for the first mode vibrating.

- far smaller than the theoretical value for modes 6-8. The reason for this disagreement may be found in out-of-plane vibrations that become important when 


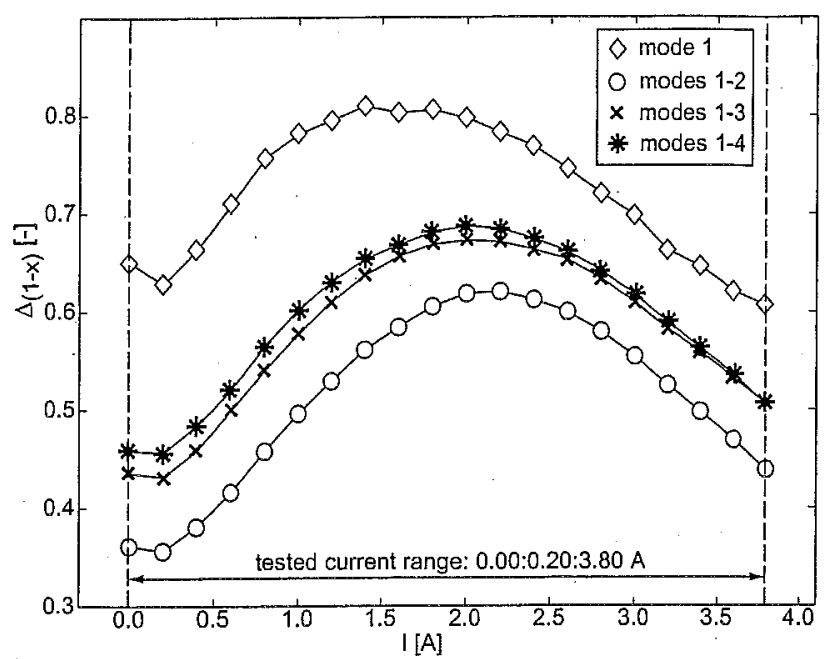

Fig. 21 a - Relative peak reduction of several targeted modes.

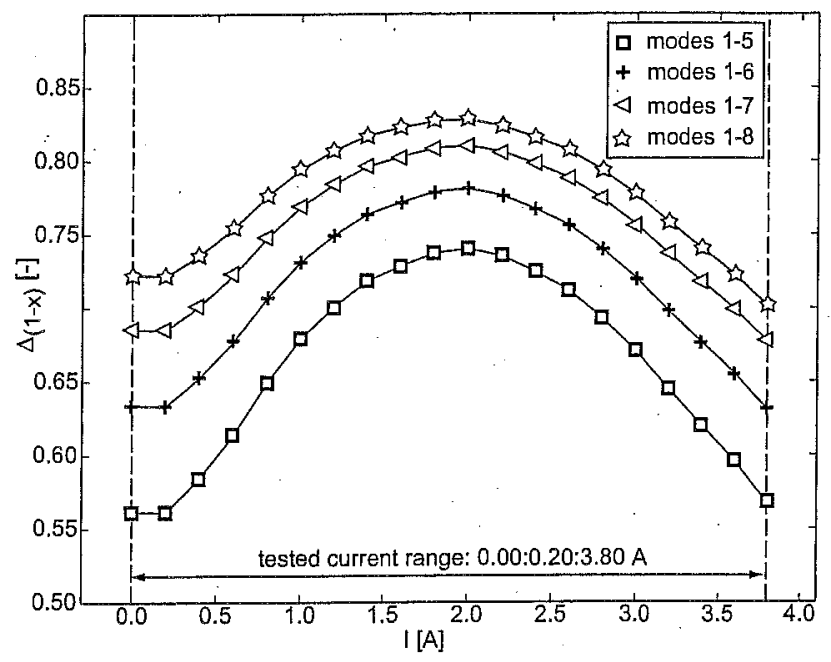

Fig. $21 \mathrm{~b}$ - Relative peak reduction of several targeted modes.

exciting higher modes. Since the MR damper works only in one plane, its force may be tuned only to the vibration component within the MR damper plane. Thus, the estimated equivalent viscosity becomes smaller than expected.

- almost not dependent on the control target 2 due to the fact that several modes have to be damped.

Moreover, the experiments clearly demonstrate that attaching external dampers to structures do not only provide additional damping but also lead to increasing resonance frequencies. This results from the fact that external dampers represent additional supports with variable damping according to the actual damper current. For large damper forces, the MR damper behaves similarly to a reasonably stiff support. Thus, the resonance frequencies increase.

\section{NOTATIONS}

\section{Abbreviations / Acronyms}

Empa Materials Science and Technology

MR magnetorheological
MRFD magnetorheological fluid damper

$P S D \quad$ power spectral density estimate via Welch's method

\section{Symbols}

$\begin{array}{lll}\text { Symbol } & \text { Description } & \text { Units } \\ I & \text { electrical current } & \mathrm{A} \\ L & \text { cable length } & \mathrm{m} \\ T & \text { cable tension } & \mathrm{N} \\ \mathcal{C} & \text { viscosity } & \mathrm{kg} / \mathrm{s} \\ f & \text { force, frequency } & \mathrm{N}, \mathrm{Hz} \\ m & \text { mass per unit length } & \mathrm{kg} / \mathrm{m} \\ n u m & \text { number } & - \\ r, \dot{r}, \ddot{r} & \text { displacement, velocity, acceleration } & \mathrm{m}, \mathrm{m} / \mathrm{s}, \\ & & \mathrm{m} / \mathrm{s}^{2} \\ x & \text { damper position } & \mathrm{m} \\ \Delta & \text { difference } & - \\ \delta & \text { logarithmic decrement } & - \\ \kappa & \text { non-dimensional damping parameter } & - \\ \omega & \text { undamped circular frequency } & \mathrm{rad} / \mathrm{s} \\ \zeta & \text { damping ratio } & \%\end{array}$

\section{Superscripts}

$\bar{a} \quad$ mean value of $a$

\section{Subscripts}

$\begin{array}{ll}\text { cou } & \text { Coulomb friction } \\ d & \text { damper } \\ i & \text { discrete time point } \\ j & \text { mode number } \\ k & \text { sensor number } \\ \text { max } & \text { maximum } \\ \text { mea } & \text { measured } \\ \text { opt } & \text { optimal } \\ s & \text { sensor } \\ \text { vis } & \text { viscous friction }\end{array}$

\section{ACKNOWLEDGEMENTS}

The authors gratefully acknowledge the technical support of the staff of the Structural Engineering Research Laboratory, the financial support of Empa, Materials Science and Technology, Dübendorf, Switzerland, and the technical support of the industrial partner Maurer Söhne GmbH \& Co. KG, Munich, Germany.

\section{REFERENCES}

[1] Xu, Z.-D., Shen, Y.-P. and Guo, Y.-Q., 'Semi-active control of structures incorporated with magnetorheological dampers using neural networks', Journal of Smart Materials and Structures 12 (1) (2003) 80-87.

[2] Spencer Jr., B.F. and Nagarajaiah, S., 'State of the Art of Structural Control', Journal of Structural Engineering 129 (8) (2003) 845-856. 
[3] Subramanian, P., "Vibration suppression of symmetric laminated composite beams', Journal of Smart Materials and Structures 11 (6) (2002) 880-885.

[4] Gordaninejad, F., Saiidi, M., Hansen, B.C., Ericksen, E.O. and Chang, F.-K., "Magneto-rheological fluid dampers for control of bridges', Journal of Intelligent Material Systems and Structures $13(2 / 3)(2002)$ 167-180.

[5] Ko, J.M., Zheng, G., Chen, Z.Q. and Ni, Y.Q., 'Field vibration tests of bridge stay cables incorporated with magneto-rheological (MR) dampers', Proceedings of the International Conference on Smart Structures and Materials 2002: Smart Systems of Bridges, Structures, and Highways, S.-C. Liu and Darryll J. Pines (eds.), Proceedings of SPIE (publ:), Vol. 4696, 30-40.

[6] Weber, F., Feltrin, G., Motavalli, M. and Aalderink, B.J., 'Cable Vibration Mitigation Using Controlled Magnetorheological Fluid Dampers: A Theoretical and Experimental Investigation', Proceedings of the International Conference on Footbridge, Paris, France, November 20-22 2002, AFGC - OTUA (eds.), on CD.

[7] Krenk, S., 'Vibrations of a taut cable with an external damper', Journal of Applied Mechanics 67 (2000) 772-776.

[8] Main, J.A. and Jones, N.P., 'Evaluation of viscous dampers for stay cable vibration mitigation', Journal of Bridge Engineering 6 (6) (2001) 385-397.

[9] 'Friction damper testing. Long cables: high results', The VSL News Magazine (issue 1) (2004) 21.

[10] Weber, B., 'Damping of vibrating footbridges', Proceedings of the International Conference on Footbridge, Paris, France, 2022 November 2002, AFGC - OTUA (eds.), on CD.

[11] Yang, J.N., Lei, Y., Lin, S. and Huang, N., 'Identification of natural frequencies and dampings of in situ tall buildings using ambient wind vibration data', Journal of Engineering Mechanics 130 (5) (2004) 570-577.

[12] Bachmann, $H$. et al., 'Vibration Problems in Structures: Practical Guidelines', ISBN 3-7643-5148-9 (Birkhäuser Verlag Basel, 1995).
[13] Tse, T. and Chang, C.C., 'Shear-Mode rotary magnetorheological damper for small-scale structural control experiments', Journal of Structural Engineering 130 (6) (2004) 904-911.

[14] Yang, G., Spencer Jr., B.F., Jung, H.-J. and Carlson, J.D., 'Dynamic Modeling of Large-Scale Magnetorheological Damper Systems for Civil Engineering Applications', Journal of Engineering Mechanics 130 (9) (2004) 1107-1114.

[15] Sims, N.D., Holmes, N.J, and Stanway, R., 'A unified modelling and model updating procedure for electrorheological and magnetorheological vibration dampers', Journal of Smart Materials and Structures 13 (2004) 100-121.

[16] Dominguez, A., Sedaghati, R. and Stiharu, I., 'Modelling the hysteresis phenomenon of magnetorheological dampers', Journal of Smart Materials and Structures 13 (2004) 1351-1361.

[17] Occhiuzzi, A., Spizzuoco, M. and Serino, G., 'Experimental analysis of magnetorheological dampers for structural control', Journal of Smart Materials and Structures 12 (5) (2003) 703-711.

[18] Liao, W.H. and Lai, C.Y., 'Harmonic Analysis of a Magnetorheological Damper for Vibration Control', Journal of Smart Materials and Structures 11 (2) (2002) 288-296.

[19] Weiss, K.D., Carlson, J.D. and Nixon, D.A., 'Viscoelastic properties of magneto- and electro-rheological fluids', Journal of Intelligent Material Systems and Structures 5 (11) (1994) $772-775$.

[20] Yang, G., 'Large-scale magnetorheological fluid damper for vibration mitigation: Modeling, testing and control', $\mathrm{PhD}$ dissertation, University of Notre Dame, Notre Dame, Indiana, 2001.

[21] Bassam, S.A., Weber, F. and Motavalli, M., 'Mitigation of cable vibrations using rubber bushings and viscous dampers', Proceedings of the $11^{\text {th }}$ International Meeting on Low Frequency Noise and Vibration and its Control, August $30^{\text {th }}$ to September $1^{\text {st }}, 2004$, Maastricht, The Netherlands, 1-14.

[22] Oyadiji, S.O., 'Controlling tube vibration using an electrorheological fluid', Journal of Intelligent Material Systems and Structures 14 (2) (2003) 113-117. 